\title{
Comparison of two approaches for carpal tunnel release: Extended versus mini-open technique
}

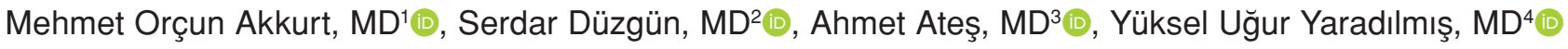 \\ ${ }^{1}$ Department of Orthopedics and Traumatology, Yıldırım Beyazıt University, Yenimahalle Training and Research Hospital, Ankara, Turkey \\ ${ }^{2}$ Department of Plastic and Reconstructive Surgery, Liv Hospital, Ankara, Turkey \\ ${ }^{3}$ Department of Orthopedics and Traumatology, University of Health Sciences, Ankara Keçiören Training and Research Hospital, Ankara, Turkey \\ ${ }^{4}$ Department of Orthopedics and Traumatology, Çankırı State Hospital, Çankırı, Turkey
}

Carpal tunnel syndrome (CTS) is the most common compression neuropathy of the upper extremity, which develops as a result of compression of median nerve at the level of wrist. ${ }^{[1]}$ The ideal surgical decompression method remains controversial and has inspired less invasive techniques such as endoscopy-assisted tunnel release (ECTR) and ultrasound-guided methods. While there are many purported advantages of ECTR, such as better patient comfort and early recovery period, ECTR and open approaches have similar long-term outcomes. ${ }^{[2]}$ The classical approach of decompression is open release of the carpal tunnel. Phalen ${ }^{[3]}$ first reported his experience and results of open carpal tunnel surgery in 1966. The classical surgical incision of the open carpal tunnel surgery extends from Kaplan's cardinal line (KCL) to wrist crease. This extended technique prevents inadequate decompression by visualization of the surgical site both proximally and distally. However, many surgeons favor shorter incisions due to unsettling scar formation after extended approach. Also, the mini- open technique has been shown to produce lower recurrence and shorter recovery period with obvious reduction in pain and

Received: September 04, 2019

Accepted: October 25, 2019

Published online: March 02, 2020

Correspondence: Yüksel Uğur Yaradılmış, MD. Çankırı Devlet Hastanesi Ortopedi ve Travmatoloji Kliniği, 18100 Çankırı, Türkiye

E-mail: ugur_yaradilmis@outlook.com

Doi: $10.5606 /$ ehc. 2020.71250

Citation: Akkurt MO, Düzgün S, Ateş A, Yaradılmış YU. Comparison of two approaches for carpal tunnel release: Extended versus mini-open technique. Jt Dis Relat Surg 2020;31(1):50-55.

\section{ABSTRACT}

Objectives: This study aims to describe a retrospective study using prospectively gathered data to compare mini-open and extended open release techniques for moderate to severe carpal tunnel syndrome (CTS).

Patients and methods: The data of 198 consecutive patients (139 males, 59 females; mean age 57.0 44.5 years; range, 44 to 75 years) treated for CPS were used. For matching, age, gender and severity of the compression, the Greathouse Ernst Halle Schaffer neurophysiological classification system was used. After matching, 63 observations in each group (group 1: mini-open and group 2: extended open) were used for analysis. A Jamar hydraulic hand dynamometer was used to measure preand postoperative third month grip strengths. The key pinch test was performed also at third month. Patients completed the Boston Carpal Tunnel Questionnaire at the last follow-up.

Results: Symptom severity and functional status were improved up to half fold in both groups at final follow-up; however, there was no statistically significant clinical difference between the groups ( $p>0.05)$. There were totally six patients with paresthesia symptoms (three in each group; $4.7 \%$ ), which improved in three months. Eight patients $(6.3 \%$, one in group 1 and seven in group 2 , $\mathrm{p}=0.032$ ) had dysesthesia and pillar pain.

Conclusion: Mini-open and extended open carpal tunnel release have similar clinical outcomes without any major complications.

Keywords: Carpal tunnel syndrome, extended release, mini-open release, matched-pair analysis.

numbness in patients having had mild to moderate CTS.$^{[4-6]}$

The literature is virtually silent regarding comparison of mini-open and extended open release for CTS. To our knowledge, the only study by Murthy et al. ${ }^{[7]}$ compared these two approaches in patients with severe CTS. The confounding data in this study regarding severity of nerve compression that can be determined by electrodiagnostic testing let us design 
a matched-pair analysis to compare mini-open and extended open release techniques. We hypothesize that extended open release is better for decompression of the nerve in patients with moderate/severe or severe CTS. Therefore, in this study, we aimed to describe a retrospective study using prospectively gathered data to compare mini-open and extended open release techniques for moderate to severe CTS.

\section{PATIENTS AND METHODS}

In this retrospective study, the data of 198 consecutive patients (139 males, 59 females; mean age 57.0 44.5 years; range, 44 to 75 years) treated for CTS at the Yıldırım Beyazıt University, Yenimahalle Training and Research Hospital between May 2011 and March 2015 were used. Indications for median nerve release were moderate/severe or severe CTS, which were defined and classified by electrodiagnostic testing according to Greathouse Ernst Halle Schaffer (GEHS) neurophysiological classification system and positive Phalen's or Tinel's tests. Exclusion criteria were patients with double crush injury, history of former surgical operation, chronic renal disease, gout, rheumatoid arthritis, thyroid disease as well as polyneuropathy, radiculopathy, plexopathy and prior steroid injections. Finally, according to inclusion and exclusion criteria, two different methods were employed on data set consisting of 178 observations. The study protocol was approved by Yildirım Beyazit University, Yenimahalle Training and Research Hospital Ethics Committee. A written informed consent was obtained from each patient. The study was conducted in accordance with the principles of the Declaration of Helsinki.

In the study, prospectively collected data were obtained from patients of whom 110 were treated by using the mini-open technique while 68 were treated by the extended open technique. Since the extended open release is not widely used, there was a difference between the sample sizes of these techniques. To overcome this difference, propensity scored matching was used on $\mathrm{R}$ programing language. In the matching procedure, logistic regression and nearest neighbor methodology were used on the variables: age (between 30-39, 40-49 and 50-59 years old), gender and preoperative GEHS classification system (moderate/ severe or severe types). After matching, 63 observations in each group (group 1: mini-open and group 2: extended open) were used for analysis. Five patients in group 2 were not included into the matching analysis due to missing data. The descriptive statistics of the two groups are given in Table I.

Of the enrolled patients ( $\mathrm{n}=126), 31(24.6 \%)$ were operated under general anesthesia, $62(49.2 \%)$ under axillary block, and 33 (26.2\%) under local anesthesia. An automated pneumatic tourniquet was used in all patients. The tourniquet pressure was planned to a level $70 \mathrm{mmHg}$ above the systolic blood pressure measured at the onset of the operation. In group 1, an incision shorter than $2 \mathrm{~cm}$ in length was performed along the ulnar side of the fourth ray and both the transverse carpal ligament and distal end of forearm fascia were released by the aid of a spatula (Figure 1). In group 2, an incision parallel to thenar palmar crease, $6 \mathrm{~mm}$ ulnar to thenar palmar crease, and extending from $1 \mathrm{~cm}$ distal to $\mathrm{KCL}$ to $1 \mathrm{~cm}$ proximal to wrist crease was performed (Figure 2). A zigzag incision towards ulnar side was planned while the incision passed wrist crease. The flexor retinaculum was released from the distal antebrachial fascia to the palmar fascia. The thenar branch was explored and preserved distal to the flexor retinaculum. The median nerve was explored under surgical binocular loop.

\begin{tabular}{|c|c|c|c|c|c|c|c|}
\hline \multicolumn{8}{|c|}{ TABLE I } \\
\hline & \multicolumn{3}{|c|}{ Group $1(n=63)$} & \multicolumn{3}{|c|}{ Group $2(n=63)$} & \multirow[b]{2}{*}{$p$} \\
\hline & $\mathrm{n}$ & $\%$ & Mean \pm SD & $\mathrm{n}$ & $\%$ & Mean $\pm S D$ & \\
\hline Age (year) & & & $57.0 \pm 1.3$ & & & $57.0 \pm 1.3$ & \multirow{5}{*}{0.729} \\
\hline \multicolumn{8}{|l|}{ Gender } \\
\hline Female & 59 & 93.7 & & 59 & 93.7 & & \\
\hline GEHS & & & & & & & \\
\hline MS & 4 & & & 5 & & & \\
\hline $\mathrm{S}$ & 59 & & & 58 & & & \\
\hline
\end{tabular}




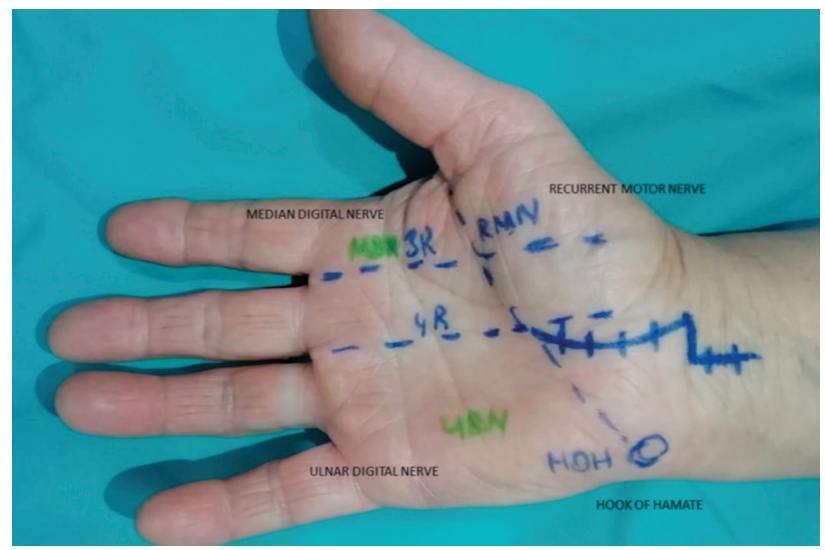

FIGURE 1. Extended approach from distal to Kaplan's cardinal line and proximal to wrist crease.

During the exploration, epineural thickening and fibrosis were observed in 26 patients (seven in group 1 and nine in group 2). In these cases, to achieve complete carpal tunnel release, neurolysis was performed with appropriate microsurgical technique. The tourniquet was deflated and hemostasis was achieved in all patients. The incisions were closed with horizontal mattress sutures using $4 / 0$ prolene. After wound dressing, the hand was splinted with a rest splint. The patients were discharged on day one. Patients were instructed to use only paracetamol when needed. No antibiotics were administered. The dressings were changed on postoperative second day and the splint was removed. The sutures were removed on postoperative $10^{\text {th }}$ day.

Patients were requested to attend to outpatient visits in the first and third months postoperatively for routine follow-up. A Jamar hydraulic hand dynamometer (Sammons Preston, Bolingbrook, IL, USA) was used to measure pre- and postoperative third month grip strengths (GS). The key pinch (KP) test was performed also at third month with the use of B\&L pinch gauge (Tustin, CA, USA). Patients completed the Turkish version of Boston Carpal Tunnel Questionnaire (BCTQ) at the last follow-up. ${ }^{[8]}$

\section{Statistical analysis}

Independent two-sample t-test and Mann-Whitney $\mathrm{U}$ test were used to compare between means of two groups. IBM SPSS version 20.0 software (IBM Corp., Armonk, NY, USA) was used to conduct the analysis. Statistical significance level of $\alpha=0.05$ was used in the analysis. Kolmogorov-Smirnov (KS) test was used for the normality assumption of the variables. According to the KS test, BCTQ symptom severity score predefined variables satisfies the normality

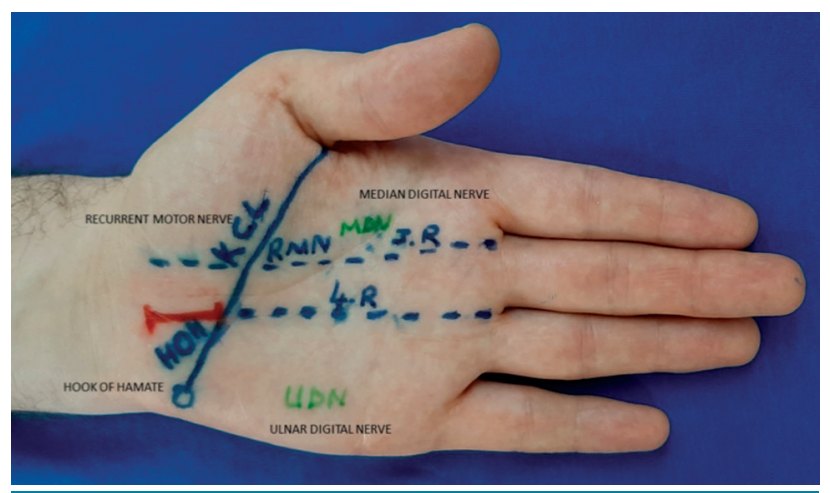

FIGURE 2. Mini-open incision for carpal tunnel release.

assumptions ( $\mathrm{p}$ value $=0.093>0.05$ ) for mini-open release and ( $p$ value $=0.20>0.05$ ) for extended open release. For the other variables, Mann-Whitney U test was used.

\section{RESULTS}

Baseline demographic parameters of two groups were shown in Table I. The mean follow-up duration was 41.7 \pm 9.4 weeks (range, 24-54 weeks) in group 1 and 41.2 \pm 9.6 weeks in group 2 (range, 23-50 weeks) and it did not differ significantly between groups $(p>0.05)$. The correlation between age and follow-up was investigated by using the Spearman correlation coefficient (rho) and the results indicated no significant relationship between the variables (Spearman Rho= -0.067 , $\mathrm{p}$ value $=0.559$ )

The detailed results of the pre- and postoperative clinical scores were shown in Table II. In both groups, statistically significant improvements $(\mathrm{p}<0.05)$ compared to preoperative measurements were achieved at the final follow-up. Although significant improvement in symptom severity and functional status were obtained in both groups at the final follow-up, there was no statistically significant clinical difference between the groups (Table I). The mean increase in GS and KP in group 1 was $19.95 \%$ and $27.05 \%$, respectively, whereas, the mean increase in group 2 was $19.35 \%$ and $24.96 \%$ for GS and KP, respectively.

In addition to comparison of the two techniques, all charts of the patients were evaluated to determine the prevalence of median nerve variations. Of 198 patients, $113(57.07 \%)$ of the thenar branch branched off the median nerve in an extraligamentous pattern distal to the flexor retinaculum. It had a subligamentous branching pattern in 57 patients $(28.78 \%)$ and a transligamentous branching 


\begin{tabular}{|c|c|c|c|c|c|}
\hline & & TABLE II & & nen & chino \\
\hline & Gro & & Gro & & \\
\hline & Mean \pm SD & Median & Mean $\pm S D$ & Median & $p$ \\
\hline GS preoperative & $23.1 \pm 1.3$ & 22.6 & $22.9 \pm 1.6$ & 34.0 & 0.729 \\
\hline GS postoperative & $27.6 \pm 1.6$ & 27.5 & $27.3 \pm 1.7$ & 26.8 & 0.192 \\
\hline BCTQ SSS preoperative & $33.6 \pm 5.1$ & 34.0 & $32.2 \pm 6.5$ & 32.5 & 0.166 \\
\hline BCTQ SSS postoperative & $16.0 \pm 2.8$ & 16.2 & $16.6 \pm 2.0$ & 16.8 & 0.172 \\
\hline BCTQ FSS preoperative & $29.6 \pm 3.2$ & 29.4 & $29.6 \pm 3.9$ & 28.6 & 0.913 \\
\hline BCTQ FSS postoperative & $14.4 \pm 2.8$ & 14.3 & $14.8 \pm 2.2$ & 14.6 & 0.440 \\
\hline Key pinch preoperative & $7.1 \pm 0.3$ & 7.1 & $7.0 \pm 0.4$ & 6.9 & 0.429 \\
\hline Key pinch postoperative & $9.0 \pm 0.4$ & 8.9 & $8.8 \pm 1.2$ & 8.90 & 0.594 \\
\hline Follow-up (weeks) & $41.7 \pm 9.4$ & 44.0 & $41.2 \pm 9.6$ & 42.0 & 0.621 \\
\hline
\end{tabular}

pattern in 28 patients (14.14\%). In four patients, an extraligamentous branch left median nerve by more than two branches (Table III).

Revision surgery was not required in any patient. Pain disappeared early at the postoperative period in all patients. Postoperatively, six patients (three in each group; 4.7\%) experienced transient paresthesia symptoms, which totally relieved in three months by anti-inflammatory medication and nutritional therapy including $B$ complex vitamin supplementation. Eight patients (6.3\%) (one in group 1 and seven in group 2, $\mathrm{p}=0.032$ ) had dysesthesia and pillar pain. Triamcinolone was injected three doses once a month and complete resolution was obtained in these patients until the end of six months.

\section{DISCUSSION}

The main finding of the present study was that both the extended and mini-open carpal tunnel release techniques provided similar functional and symptom severity scores. However, extended release led to a higher rate of incision-related complications $(n=7)$ compared to the mini-open $(n=1)$ technique.

\section{TABLE III}

Variations of thenar motor branch found in this study

\begin{tabular}{|lcc|}
\hline & $\mathrm{n}$ & $\%$ \\
\hline I. Extraligamentous & 113 & 57.07 \\
II. Subligamentous & 57 & 28.78 \\
III. Transligamentous & 28 & 14.4 \\
IV. Extraligamentous with two branching & 4 & 2.02 \\
\hline
\end{tabular}

Superiority among open or mini-open techniques for carpal tunnel release remains highly controversial in the orthopedic literature and among surgeons. Using a retrospective study, Murthy et al. ${ }^{[7]}$ reported no significant differences between the two procedures with regard to patient-rated symptom severity or functional status outcomes. Although this study presented a large cohort of severe CTS patients, they were not adequately matched between the two groups with regard to age, gender and preoperative electrodiagnostic testing. In this study, a matched-pair design was chosen to achieve adequate comparability by minimizing confounding factors.

Conventional open carpal tunnel release, miniopen release, ultrasound-guided technique and ECTR are the three main and frequently used surgical treatment techniques for CTS. Among them, extended open technique for CTS is accepted to be an effective and safe method since the thenar branch has anatomic variations. ${ }^{[9]}$ However, the most common complication of carpal tunnel release is injury to the palmar cutaneous branch of the median nerve (PCBMN) and subsequent neuroma formation leading to scar tenderness. Although the cause of dysesthesia is not yet fully understood, higher rate of scar discomfort in the extended open release group may be attributed to the injury of PCBMN and subsequent neuroma formation. In a cadaveric study, Ozcanli et al. ${ }^{[10]}$ aimed to define the safe zone for mini-open release in 30 hands and they identified similar rates of thenar branch variations as in our study. They also described a safe zone for mini-open release in order to prevent any injury to the PCBMN as being between the PCBMN and superficial palmar arch. 
Endoscopic release is the prevailing option for carpal tunnel decompression. Although it was suggested that ECTR leads to better recovery and earlier return to work and that it is safer than open techniques, it was reported that late satisfaction from ECTR is no different than open techniques. ${ }^{[11,12]}$ The high early satisfaction rate and improved patient comfort popularized ECTR; however, concerns for lacerations of important neurovascular structures, anatomic variations and ancillary issues such as cysts, tenosynovitis, calcific tendinitis, schwannoma and amyloidosis, technical difficulty and cost-effectiveness still prevent general use of this technique. ${ }^{[13]}$ Sensory loss in the third or fourth fingers has been reported to be high due to incorrect positioning of the cannula leading to digital nerve injury in the endoscopic carpal tunnel release. Also, endoscopic technique is prone to thenar branch injury due to the variations of the anatomical branching. ${ }^{[14,15]}$ The latter is also responsible for the risk of median nerve injury during endoscopic technique. Boecksyns and Sorensen ${ }^{[16]}$ reported a rate of $0.3 \%$ for irreversible median nerve injury after endoscopic median nerve release surgery. Thoma et al. ${ }^{[17]}$ observed three times more common nerve injury during endoscopic technique compared to open technique.

Limitations of this study should also be acknowledged. First, due to the retrospective nature of this study, some data such as Semmes-Weinstein monofilament testing may not have been collected accurately, and more importantly, the severity of the compression was only determined according to the GEHS classification which relies solely on electrodiagnostic testing. Second, no post hoc power analysis was conducted because it would not be comparable to a priori power analysis, in fact, estimates of true power in a retrospective study will never exceed 0.53 , and thus it would be not only useless but also misleading. ${ }^{[18]}$

In conclusion, the results of this matched-pair study demonstrated that mini-open and extended open carpal tunnel release have similar long-term clinical outcomes without any major complications. However, extended technique has higher rate of scar discomfort due to lengthier incision potentially injuring the PCBMN. Future studies are necessary to determine the reasons of scar discomfort.

\section{Declaration of conflicting interests}

The authors declared no conflicts of interest with respect to the authorship and/or publication of this article.

\section{Funding}

The authors received no financial support for the research and/or authorship of this article.

\section{REFERENCES}

1. Rempel D, Evanoff B, Amadio PC, de Krom M, Franklin G, Franzblau A, et al. Consensus criteria for the classification of carpal tunnel syndrome in epidemiologic studies. Am J Public Health 1998;88:1447-51.

2. Oh WT, Kang HJ, Koh IH, Jang JY, Choi YR. Morphologic change of nerve and symptom relief are similar after mini-incision and endoscopic carpal tunnel release: a randomized trial. BMC Musculoskelet Disord 2017;18:65.

3. Phalen GS. The carpal-tunnel syndrome. Seventeen years' experience in diagnosis and treatment of six hundred fiftyfour hands. J Bone Joint Surg Am 1966;48:211-28.

4. Cellocco P, Rossi C, Bizzarri F, Patrizio L, Costanzo G. Miniopen blind procedure versus limited open technique for carpal tunnel release: a 30-month follow-up study. J Hand Surg Am 2005;30:493-9.

5. Avci S, Sayli U. Carpal tunnel release using a short palmar incision and a new knife. J Hand Surg Br 2000;25:357-60.

6. Gaba S, Bhogesha S, Singh O. Limited incision carpal tunnel release. Indian J Orthop 2017;51:192-8.

7. Murthy PG, Goljan P, Mendez G, Jacoby SM, Shin EK, Osterman AL. Mini-open versus extended open release for severe carpal tunnel syndrome. Hand (N Y) 2015;10:34-9.

8. İlhan D, Toker S, Kilıncıoğlu V, Gülcan E. Assessment of the Boston questionnaire in diagnosis of idiopathic carpal tunnel syndrome: Comparing scores with clinical and neurophysiological findings. Düzce Tip Fakültesi Dergisi 2008;10:4-9

9. Henry BM, Zwinczewska H, Roy J, Vikse J, Ramakrishnan PK, Walocha JA, et al. The Prevalence of Anatomical Variations of the Median Nerve in the Carpal Tunnel: A Systematic Review and Meta-Analysis. PLoS One 2015;10:e0136477.

10. Ozcanli H, Coskun NK, Cengiz M, Oguz N, Sindel M. Definition of a safe-zone in open carpal tunnel surgery: a cadaver study. Surg Radiol Anat 2010;32:203-6.

11. Alp NB, Akdağ G, Macunluoğlu AC. Median nerve and carpal tunnel volume changes after two different surgical methods: A comparative magnetic resonance imaging study of mini-open and endoscopic carpal tunnel release. Eklem Hastalik Cerrahisi 2019;30:212-6.

12. Aslani HR, Alizadeh K, Eajazi A, Karimi A, Karimi MH, Zaferani $Z$, et al. Comparison of carpal tunnel release with three different techniques. Clin Neurol Neurosurg 2012;114:965-8.

13. Calotta NA, Lopez J, Deune EG. Improved Surgical Outcomes With Endoscopic Carpal Tunnel Release in Patients With Severe Median Neuropathy. Hand (N Y) 2017;12:252-7.

14. Lutsky KF, Jones CM, Kim N, Medina J, Matzon JL, Beredjiklian PK. Frequency of incidental median thenar motor nerve branch visualization during mini-open and endoscopic carpal tunnel release. Hand (N Y) 2017;12:60-3.

15. Mathen SJ, Nosrati NN, Merrell GA. Decreased rate of complications in carpal tunnel release with hand fellowship training. J Hand Microsurg 2018;10:26-28.

16. Boeckstyns ME, Sørensen AI. Does endoscopic carpal tunnel release have a higher rate of complications than 
open carpal tunnel release? An analysis of published series. J Hand Surg Br 1999;24:9-15.

17. Thoma A, Veltri K, Haines T, Duku E. A meta-analysis of randomized controlled trials comparing endoscopic and open carpal tunnel decompression. Plast Reconstr Surg 2004;114:1137-46.

18. Thomas L. Retrospective power analysis. Conservation Biology 1997;11:276-80. 